\title{
ITs in Engineering Education: Joining Efforts Be- tween SPEE and IGIP
}

http://dx.doi.org/10.3991/ijep.v2i1.1899

\author{
A. Cardoso ${ }^{1,7}$, Carlos Vaz de Carvalho, ${ }^{2,7}$, Fernão de Magalhães ${ }^{3,7}$, Pedro Neto ${ }^{4,7}$, M. Graça Rasteiro ${ }^{1,7}$, \\ Maria Teresa Restivo ${ }^{3,6,7}$, Danilo G. Zutin ${ }^{5,6}$, Bill Williams ${ }^{4,7}$ \\ ${ }^{1}$ University of Coimbra, Coimbra, Portugal \\ ${ }^{2}$ GILT - Instituto Superior de Engenharia do Porto, Porto, Portugal \\ ${ }^{3}$ Universidade do Porto, Portugal \\ ${ }^{4}$ Setubal Polytechnic Institute, Portugal \\ ${ }^{5}$ Carinthia University of Applied Sciences, Villach, Austria \\ ${ }^{6}$ International Society for Engineering Education (IGIP), Austria \\ ${ }^{7}$ Sociedade Portuguesa para Educação em Engenharia (SPEE), Portugal
}

\begin{abstract}
The International Society for Engineering Education (IGIP) and The Portuguese Society for Engineering Education (SPEE), the first being the oldest European Society for Engineering Education in Europe and the second the very young Society for Engineering Education in Portugal, have been intensifying the collaboration between the two societies as well as the exchange and dissemination of information about their relevant activities, whilst promoting understanding and cooperation between their respective members. One possible way is to create joint working groups, open to the members of both societies, on common topics of interest. In fact, both societies already kicked off this activity. The first initiative happened during the $1^{\text {st }}$ World Engineering Education Flash Week (WEE), Lisbon, 2011. The SPEE-IGIP Flash Moment was a one day event integrated in the main Conference, which was dedicated to "Information \& Communication Technologies in Engineering Education".
\end{abstract}

ITs allow the development of different teaching strategies which contribute to enhance the learning outcomes of students. ITs are also particularly suited to develop Life Long Learning tools, in a broad range of Engineering subjects, either open to the general market or oriented to a very specific public.

Examples of teaching strategies involving ITs have been addressed during the Flash Moment SPEE-IGIP which took place during WEE, and some are described in detail in the present work.

Index Terms-Continuing education, Remote sensing, Virtual reality, online labs, online assessment, haptic interfaces.

\section{INTRODUCTION}

The International Society for Engineering Education (IGIP) - was founded in 1972 at the University of Klagenfurt (A). Establishing an engineering pedagogy was a step forward at that time, engineering and pedagogy had never been linked before on a scientific level. Even in the seventies, European integration and standardized profiles for educators were seen as most important factors of education, training and learning. Therefore, IGIP established an international register of engineering educators, which guarantees minimum standards in technical expertise and a well-balanced competence profile for engineer- ing educators. The register lists qualified educators who had gone through a curriculum which has been approved by IGIP. Those registered are International Engineering Educator and can use the title ING.PAED.IGIP. IGIP accredits training centers for "International Engineering Educators", whose teaching matter conforms to IGIP's curriculum for engineering pedagogy. IGIP has about 700 members in 57 countries and has consultative status with UNESCO and UNIDO.

The Portuguese Society for Engineering Education (SPEE) was founded in 2010 at the Faculty of Engineering of University of Porto (FEUP). The main objectives of SPEE are the promotion of education through teacher training, projects dissemination, exchange and cooperation between individuals and institutions and fostering problem analysis and solution within engineering education, in close cooperation with similar societies in Europe and worldwide. To this end SPEE has set up a number of working groups (Ethics in Engineering, IT's for Engineering Education, Lifelong Learning in Engineering, Mathematics in Engineering Education and Tools to Develop Higher Order Thinking Skills) and wishes to promote cross fertilization with similar groups in other societies. Considering the important role of students in an Education Society, SPEE is looking for their inclusion as individual members. Presently, SPEE has over 200 individual members and 20 institutional members in Portugal and a few from the American Continent. SPEE has been actively involved in the process of curriculum proposal for accreditation of FEUP as IGIP training center for "International Engineering Educators", which was successfully approved in September 2011.

On November 2011 the Presidents of IGIP and SPEE signed a Memorandum of Understanding (MoU) between both societies. As main goal both Presidents "are willing to encourage close collaboration between the two societies as well as the exchange and dissemination of information about their relevant activities, whilst promoting understanding and cooperation between their respective members." Membership, Regular Events, Possible other Joint Activities and Special Events are the topics considered in this MoU. One possible other joint activities looks for the creation of joint working groups, open to the members of both societies, on common issues of interest. 
PAPER

ITS IN ENGINEERING EDUCATION: JOINING EFFORTS BETWEEN SPEE AND IGIP

In fact, both societies already kicked off this activity. The first initiative happened during the 1st World Engineering Education Flash Week WEE, Lisbon, 2011.

The SPEE-IGIP Flash Moment was a one day event, integrated in the main Conference, which was dedicated to "Information \& Communication Technologies in Engineering Education" (http://wee2011.com/index.php?op

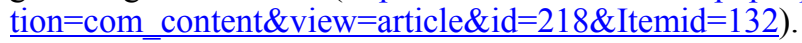

ITs allow the development of different teaching strategies which contribute to enhance the learning outcomes of our students. These strategies can include on-line laboratories, which are well suited to collaborative teaching, and which need global initiatives for their better and more efficient development and sharing. Regarding on-line laboratories different approaches are possible: remote, virtual, virtual reality, hybrid experiments, remote haptic interaction with experiments and multimedia contents. Additionally, the on-line teaching tools can be coupled with in-classroom systems or, alternatively, it can be used to better prepare students to enter, later, the real laboratory, making a more efficient use of the time spent in the real lab.

On the other hand, ITs are particularly suited to develop Life Long Learning tools, in a broad range of Engineering subjects, either open to the general market or oriented to a very specific public as required by a certain economic sector, which may include assessment of the education outcomes. In this area, new approaches involve development of self and peer assessment tools, which can contribute to better tune learner and instructor, as well as to provide useful data for educators, being an important component of collaborative group-work.

All these different teaching strategies involving ITs have been addressed during the joint session SPEE-IGIP which took place during the "1st World Engineering Education Flash Week" in 2011, in Lisbon, and some of them will be described in more detail in the next sections of this paper.

\section{Global InItIATIVES FOR PROMOTING THE DEVELOPMENT AND SHARING OF ONLINE LABS}

The excessive supply of broadband Internet connection especially at the end of the last decade has pushed educators to seek innovative ways to support learning [10]. Important outcomes of these efforts are online laboratories. Several universities, schools and other organizations adapted their programs to offer, in addition to their traditional laboratories, online labs in different scientific fields. As traditional laboratories are already an essential part in science and engineering courses, no fundamental changes in the curricula had to be implemented. Like traditional laboratories this type of laboratories provides students with particular engineering experience and allows them to explore systems and their real behaviours. In this way, lab assignments and experiments carried out in a traditional laboratory should be feasible without or with minimal changes in online environments. Online laboratories can be extremely useful for carrying out experimentation from home and can add value to distant learning study programs. Another scenario for the application of online laboratories is when educators want students to acquire introductory hands-on experience and familiarize themselves with real-life devices prior to laboratory practice. In this way, efforts could be focused more in the experiment itself rather than in the familiarization with the lab equipment [1].

Although, the growing number of online lab solutions pose some constraints especially regarding their sharing and usage. There are some initiatives addressing these issues, like the MIT iLab Shared Architecture, that focuses in providing a software platform that offers a common framework for sharing and managing labs as shown in [2].

Another issue that poses constraints to the dissemination is that online laboratories are often hidden from the education community. The most significant reason for this problem is the current lack of information about online laboratories that provide potentially interested people the ability to search for adequate laboratories and contact their developers, instructors or users and exchange experiences or even access to the online laboratory [9]. This lack of information regards almost everyone in the online laboratory community as students, administrators as well as professors even if this influence them in different manners. The fundamental problem is the lack of information which describes the resources or being more specific, the lack of a metadata schema to describe these resources. This has also been addressed by some initiatives like Lab2go, an online laboratory portal in the form of a repository. The Lab2go is implemented as a Wiki and is therefore open to the public. It provides furthermore mechanisms to search for information based on very specific criteria, what improves the search outcomes significantly [9]. Lab2go also focuses in providing a model of this specific knowledge domain and uses semantic Web technologies to model it and is therefore in line with the future trends of the Web [3-8]. Currently other initiatives like GOLC (Global Online Laboratory Consortium) are addressing these issues to create a standard metadata schema.

\section{CASE StUdies}

\section{A. Is a virtual lab any good?}

Experimental activity plays an important role in Engineering Education [10] and it has been included in engineering curricula since ever. Hands-on activity provides students with methodologies to tackle concrete tasks, to interpret and discuss results, to inquire about the used techniques, to understand procedures and concepts in action, helping them to clarify their scientific conceptual background and to practice their ability for problem analysis and solution. The practice in finding different real possible solutions, selecting the one that best fits the problem, and not only one correct solution for the problem traditionally solved in a sheet of paper, is an important step for the development of a future engineer.

The NET Generation [11], today's young people, is generally attracted by the technology. They are commonly compulsive tech consumers. It is essential to take advantage from this universal characteristic. So, information technologies have to be a must in the teaching/learning process. And in this perspective it is out of question the recurrent discussion on the validity of remote and virtual labs (RVLs). They will never substitute the real task at the lab, but they will be an important complement. So, RVLs can potentiate the learning activities even considering the lifelong learning process, also in 
constant change and they can bring great advantages in training activities, as well.

This NET Generation is used to get everything at the distance of a click. Teachers need to be aware, to understand seriously and to find their own option in how to make good use of IT's for helping students understand the real evidence of concepts in successful and consistent ways [11], stimulating collaborative work, creating and sharing knowledge, re-using available resources and sharing their own resources in multicultural participation for enlarging knowledge frontiers and increasing development.

And now is the time for the opening question - is a virtual lab any good?

In a virtual experiment the user interaction is restricted to a computer environment based in a developed application supported by a system model. And this is pleasantly flexible for nowadays youngsters' profile!

A virtual experiment may be accessed remotely or uploaded to the user PC with the freedom and the flexibility coming from their virtual quality [12]. If the virtual experiment is well structured and designed, it could be of higher cognitive stage for training purpose. Therefore many industries already make similar use of virtual systems for training.

An open access example developed in open source software will be used embodying reasons for the question suggested [13].

The virtual Michelson Interferometer from the Faculty of Engineering of University of Porto will be used as a nice example of well structured, rigorous and well designed replica offering a user friendly interface and an amazing flexibility impossible to get in any real system.

In the engineering area this system is of interest in different contexts: it is used in metrological labs for $\mu-$ displacement measurement as a gold standard, allowing resolutions ofn $1 / 4 \lambda$ of the beam laser radiation. This system is also used in automation and for calibration procedures in machine tool equipment, among other Michelson Interferometer working principle applications.

In general terms a Michelson Interferometer is a set of different components: a laser or a fiber optical laser, lens, mirrors and one beam splitter. The laser is responsible for delivering a monochromatic light beam. A beam splitter, if angled at $45^{\circ}$ to the laser beam, is used for splitting the light beam into two beams. If so, the initial laser light beam will be separated into two at the same point in space due to partial reflection through the beam splitter and the other half will be reflected at an angle of $90^{\circ}$.

These two half beams will travel along different optical paths. In front of each there are two front surface mirrors. So, both half beams will be reflected and they will merge to produce interference fringes visible if reaching a screen. A diverging lens receiving this final beam before reaching the screen could be used to magnify the interference fringes on the screen.

One of the mirrors is fixed, while the other is a moving mirror along one of the half beam directions and so, the optical paths could become different according to the displacement. This will cause consecutive light and dark fringes. Therefore, the interference fringes will be sliding from a bright fringe to a dark one. If the moving mirror is under an almost unperceivable movement (of microme- ter's amplitude), the fringes will be visibly shifting. Changes in the movement direction will produce fringes shifting in the opposite direction.

Fig. 1 shows a 2D simulation of a laser beam of a given diameter. The red and green colors were used to delimit the light beam. The moving mirror on the left can slide forward and backwards causing different light paths. The fixed mirror can be adjusted normal to the other laser beam. When aligning a mirror, some errors of micrometers of magnitude could easily be introduced. All these consequences could be observed in the on-off state of two leds on the limiting laser beam rays (red and green). Now, it is also easily understandable that, if the medium's index of refraction changes, then the light path will be slightly different and so a fringe shift will happen. This gives another perspective for the use of a Michelson Interferometer.

When this process is understood by training with the described simulation then the user should feel confident for manipulating the virtual Michelson Interferometer freely downloadable from (http://remotelab.fe.up.pt/ otherexperiments.html), (Fig. 2).

The "how to use" written tutorial can be used, simultaneously, with a demo video clip, both available at http://onlinelab.fe.up.pt/otherexperiments.html.

This is an example of a 3D virtual replica of a real system that exists in one of the Physics labs at FEUP, which has been adapted to be accessible on-line [14]. However, constraints of this remote experiment are clear when compared with the flexibility of this novel simulator. Many examples of nice virtual systems are known, as is the case of the following references, [15-17]

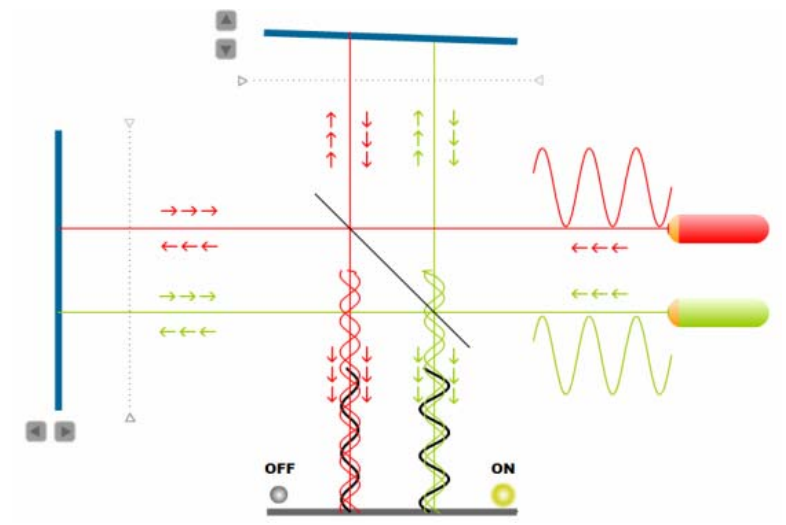

Figure 1. Simulation of interference fringe

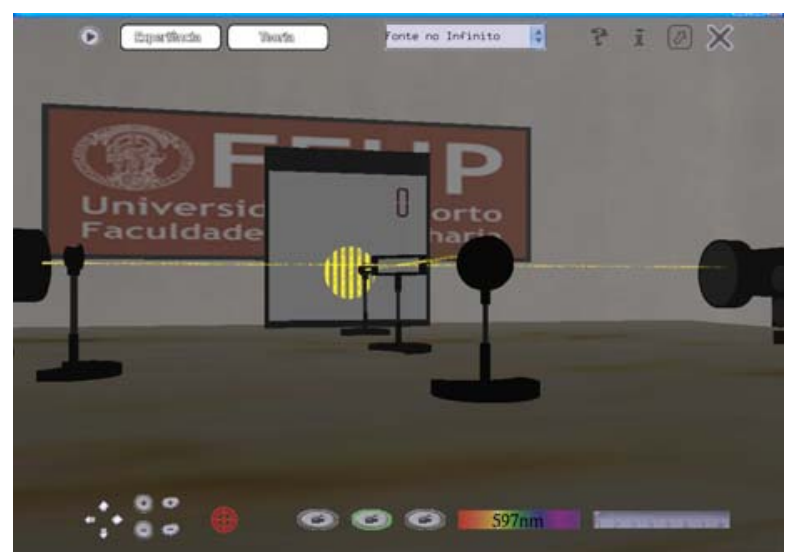

Figure 2. Virtual Michelson Interferometer 


\section{B. Haptic Systems to Learn Basic Sciences in Engineering}

The experiential learning theory is based on the importance of experimenting and experiencing. The theory proposes a sequence of experimentation, observation, reflection and abstract conceptualization so that theoretical concepts are applied in real or quasi-real contexts to consolidate learning. But these concepts can also be derived from reflection upon experimentation.

Formal education must be prepared to use a new generation of learning tools and to develop these tools for learner autonomy, cooperation, creativity and critical analysis. Learning with these tools should emphasize visualizing, hearing, feeling, experimenting and interpreting so that there is an effective construction of knowledge [18].

The use of Virtual Reality (VR) environments for experiential learning benefits from advanced interaction technologies, like haptic devices - a tactile sensory interface between a person and a computer - that create highly realistic and immersive environments.

Haptic devices are an important component of multisensory communication. The word haptic is an adjective that means "relative to the touch, touch". It denominates the science of touch and the study and simulation of pressure, texture, vibration and other meanings expressed through touch. Therefore, haptic devices reproduce feedback forces that an object produces when touched.

The purpose of VR technologies is then to mimic reality in order to amplify the feeling of truth to the user. The great advantage of this type of interface is that the intuitive knowledge of the user's physical world becomes beneficial to master the virtual world.

The proposed virtual experiential learning methodology is based on the Dewey 3-stage learning cycle: experience-reflection-learning [19]. Following the ELM model, students are lead to experience, to act, to observe the consequences of their actions and to reflect on the results. However, the fact that this is a cycle implies that students can start anywhere. In fact, according to Dewey, we could also define the cycle by the expression: experience + reflection $=$ learning [19].

Initially, an aerodynamics simulation environment was created. In this simulation, the phenomenon under study is the movement of air and the consequent behavior it produces in certain objects, such as the wings of an airplane. This behavior and the corresponding forces are reproduced in the haptic device.

A wind tunnel was the scenario depicted in the simulation for the study of aerodynamic phenomena of the flight of an airplane. The interface of the simulator shows a plane P-38 Lightning, a graphic with the magnitude of the four aerodynamic forces and data on the speed, angle of attack and status of the airplane, i.e. tells if the airplane is on the take-off, climbing, cruise flight, etc.

A second experiment involved the creation of VR scenarios for learning the theory of friction. Friction relates to forces that are created whenever two surfaces in contact move or try to move.

For this experiment, the most relevant friction force is the sliding friction: when two solid objects are in contact and a force is applied to slide one object against the other, the sliding friction force resists the motion. If $\mathrm{F}$ is the force pushing on an object and F0 is the force of friction, the relationship between $\mathrm{F}$ and $\mathrm{F} 0$ will determine whether the object will slide or not move at all.

The validation of the simulations was conducted with two groups (25 students in each group, $90 \%$ male, average 18 years-old) of the first year of the Computer Engineering degree from ISEP (Instituto Superior de Engenharia do Porto).

To assess the perception of the students in relation to the effectiveness of this learning methodology, they were asked to answer the following set of questions:

- The application is intuitive? $79 \%$ of the students answered that the application was highly intuitive. Only 9\% didn't find it intuitive.

- The application offers a better understanding of the physics? $90 \%$ of the students replied positively.

- The experiential style of haptic systems applied to education gives greater motivation to learn? $90 \%$ of the students replied positively.

- Haptic systems should be applied to other disciplines? All the students replied positively.

In what concerns the knowledge acquisition it was clear that, by being immersed in the simulation environment, students were able to relate theoretical concepts and the practice. Collected results show that physics understanding was greatly enhanced and that students' motivation for learning, even theoretical concepts, was increased.

\section{Student experimentation in process control: remote access versus in-classroom systems}

The present work was prompted by an actual necessity, identified at a Process Control course in the Chemical Engineering Integrated Master's degree at FEUP. In addition to amphitheatre classes, this course includes a weekly class session taking place in a computer room. These classes were traditionally used for work with Matlab/Simulink. Our challenge was to introduce interaction with real systems in some of these classes, trying to avoid the pitfalls of control practice based uniquely on mathematical simulation.

The first approach considered was web-based access to an existing lab setup for liquid level control on a two tank cascade [20]. Browser integration was implemented using LabVIEW's web server capabilities. The setup allowed continuous operation without need of local interaction, all user actions being integrated in the software interface. In addition to providing contact with a realistic system, this experiment presented fast response times, allowing for inclass exercises to be performed in reasonable times. However, only one user at a time can operate the interface. Even though the system behaviour can be monitored and then analyzed by the entire class, this restricted interaction represents a disadvantage and limits student interest. In addition, the software interface was not representative of interaction with an industrial controller. This remote access experiment was therefore adopted solely for teacher-led demonstrations in amphitheater classes and off-class student projects.

The second approach consisted on the development of small-scale portable setups that could be easily taken to class for student groups to work with. A temperature control system was chosen, as it is a relevant concept in 
PAPER

ITS IN ENGINEERING EDUCATION: JOINING EFFORTS BETWEEN SPEE AND IGIP

Chemical Engineering and can be implemented in a small, self-contained, unit. The basic idea consisted in controlling the temperature in the back surface of a $25 \mathrm{~W}$ halogen lamp. A thermocouple, touching the surface, is connected to a small size Eurotherm temperature controller. The controller acts on a solid state relay, switching the lamp on and off cyclically, so that the effective heating power varies continuously between 0 and $100 \%$. A cooling fan is also connected to the controller, through a simple relay output, being activated when the surface temperature exceeds the intended set-point by a certain threshold amount. The system also includes an AC/DC 12 $\mathrm{V}$ transformer, which powers both the lamp and the fan. The unit resembles a box with $22 \times 16 \times 10 \mathrm{~cm}$, with the temperature controller panel embedded on the front face. The top and side covers are made of transparent acrylic, so that all wire connections can be easily visualized. Six such units were built, each costing about $250 €$ plus tax. These can be easily carried to class, and are safe and robust for student operation. Students are divided into groups of 3 or 4 elements, each working with one unit on proposed exercises. Lamp surface temperatures along time are manually logged onto a spreadsheet application and treated as necessary.

Some practical exercises that have been successfully implemented with these portable units are: dynamic system identification (determination of thermocouple transfer function), analysis of PID controller performance (response analysis for different sets of PID parameters), and implementation of different controller tuning methodologies (e.g. Ziegler-Nichols continuous cycling, process reaction curve, auto-tuning).

These units allow in-classroom student interaction with an industrial controller acting on a realistic system, improving motivation and self-confidence for future professional work. The fact that several units can be built for a controlled cost allows for simultaneous operation of several student groups. Fast response times insure that exercises can be completed during class time.

\section{Using Online Experiments to Prepare Students for Lab Classes}

The practice of making available on-line different types of tools to help students in their learning process is spreading in many higher education institutions, and in many scientific fields, namely in what concerns Engineering Education [21-22]. On-line laboratories are one of the approaches followed by many institutions, be it virtual or remote laboratories.

In the case of Chemical Engineering education, there are some experiences going on in several universities, namely at MIT/USA, University of Tennessee /USA, Cambridge University/UK, Seoul National University/Korea, Leipzig University/Germany, Indian Institute of Technology/India, and also at both the Universities of Coimbra and Porto in Portugal.

In this last case the on-line experiment developed are included in a wider platform directed to the teaching of chemical processes (LABVIRTUAL http://labvirtual.eq.uc.pt) [20], which includes different but converging approaches to the student learning process: multimedia libraries, simulators incorporating case studies and virtual experiments. The backing strategy is the belief that the fundamental concepts in the multimedia libraries sections constitute a necessary background for the students to use both the design simulators and the virtual experiments in an informed way, improving the efficiency of these tools on their learning process. Moreover, the case studies help the students in a more efficient use of the simulators. Regarding the on-line experiments they supply to the students the necessary visualization of the mechanisms involved in several of the processes which can be designed using the simulators.

On the other hand, the platform deals with a wide range of chemical processes such as: Reaction Engineering; Separation Processes; Biological Processes as well as with the Control and Optimization of those processes. As a consequence, both due to the approach followed to address the different processes (multimedia libraries, simulators and virtual experiments), and due to the wide range of processes being available in the same platform, this instrument constitutes an optimum tool for knowledge integration, which was always one of the main objectives of the team behind this project.

Four experiments are included, so far, in the section of "virtual experiments": determination of the kinetic constant and activation energy for the liquid phase homogeneous reaction between ethyl acetate and sodium hydroxide; flow pattern characterisation in a tubular reactor packed with glass beads; study of the sucrose inversion and study of a cation-exchange resin. In addition to the description of the experimental setups and procedures and the theoretical background for each experiment, multimedia support is provided in the form of video, illustrating the components of each experiment and the major steps in the operation procedures and experimental episodes. The experimental results collected and their treatment are also illustrated. Finally, a template for a short report of each work is provided.

In this context, on-line experiments enable the students to visualize some basic phenomena and mechanisms on which the design of chemical processes is based, and also help them to be better prepared to enter the real laboratory, where time is scarce and more expensive. It is our perspective that experimentation is essential for the education of Chemical Engineers, but, and because of that, efforts must be pursued to help the students in getting the most from time spent in the real laboratory. It should be stressed that besides the described simulations and the possibility of viewing the video corresponding to the experiment on the platform, the students will always perform, as well, experiments in the laboratory. The analysis of the results for reporting may be done using the simulators, which offer the capability to test different aspects of the process in a very efficient way.

In the future, we plan to develop a lab report management and a verification tool. This will include, among other features, e-mail report delivery management, validation of lab results, computation of parameters from reported data, comparison between the "expected" parameters and the reported ones.

\section{E. Using wireless sensor networks for remote temperature monitoring}

In the last few decades there have been considerable and consistent efforts in developing remote and virtual labs (RVL) as web-based education tools and platforms for students and technicians in lifelong learning programs, where the inherent flexibility and adaptability of such systems are greatly appreciated [23]. 
PAPER

ITS IN ENGINEERING EDUCATION: JOINING EFFORTS BETWEEN SPEE AND IGIP

This new paradigm of learning and training enables to develop a system rich in educational content that is practical, flexible and easy to access, breaking down spatial and temporal barriers of the traditional approaches. Students and trainees may accomplish their own experiments from her/his laptop, just requiring the availability of an internet connection to have access to different kinds of virtual or real plants and experiments in a e- or b-learning context and for enriching the class room activities.

As expected, several courses in different degrees are currently taking advantage of all the potential of the Information Technologies, namely, the Internet infrastructure and web technologies, to develop and implement distant teaching and learning paradigms. In a web-based virtual laboratory students or trainees use the internet or an ethernet local area network (LAN) to perform experiments on setups expressed in the form of models of plants, being the virtual system's time response emulated by simulation on a fast processor server. In the case of remote laboratories, users, instead of performing virtual experiments, can have access to real pilot plants, connected via data acquisition boards or wireless sensor networks to a server computer.

The integration of RVL in intelligent tutoring systems (ITS) represents an approach to build web platforms with capability of adaptation to different users' profiles. The ITS should be able to define contents and propose experiments according to the specific needs and backgrounds of each user. In particular, students from secondary education levels, engineering courses and trainees from industries have different profiles and the system should be developed taking into account their specific characteristics and needs. In general, the use of a ITS can provide advantages in the student's and trainee's exploration and interaction by creating adequate sequences of experiments and following up the user's performance in real time, using, for example, task planning to enhance the user's learning performance and providing feedback, help and guidance to address the user's immediate problems and needs [23-24].

The RVL@DEI-UC is a hybrid web based platform with interactive computer applications that allows users to carry out remote and/or virtual experiments using real physical systems that can be remotely or locally accessed and controlled through a web browser. The experiments provided to each user through the intelligent tutoring system are selected according to its profile, background and the characteristics of the course [24].

The remote monitoring of temperatures using a wireless sensor network is an example of a remote experiment that can be integrated in courses for different subjects. In this framework, sensors spatially distributed to read several temperatures are connected through nodes of the wireless network to a gateway that provides the data to the platform.

It is expected that the integration of remote and virtual experiments in tutoring systems with mechanisms of identification, monitoring and supervision of users' behaviour and progress could improve the users' performance and accomplishment of the tasks proposed in each course's module.

\section{F. The use of an on-line tool for self and peer} assessment, a Technology Stewardship Approach

Self and peer assessment (SPA) is often considered an important component of collaborative group-work [2526], because it can reduce the possibility of free-riders in group projects while at the same time giving learners practice in exercising judgment which can be an important professional competence in itself [27-29].

With the increasing emphasis on quality assurance and accountability in European higher education [30] and a rapid proliferation of IT technology and tools which make claims to help achieve this, educators here have been increasingly faced with decisions relating to tool design and selection - issues described by [31] as falling within the domain of technology stewardship. Wenger et al state: "Technology stewards are people with enough experience of the workings of a community to understand its technology needs, and enough experience with technology to take leadership in addressing those needs. Stewardship typically includes selecting and configuring technology, as well as supporting its use in the practice of the community". While the concept was originally proposed from an informal learning community perspective, many higher education practitioners may recognize this as describing a growing portion of their professional activity although those of us in the engineering education domain would also want to emphasize tool design as part of the remit of technology stewards.

Since the publication of their book Digital Habitats [31] the concept of technology stewardship has begun to be applied in a variety of learning communities and the authors have found it particularly useful in our work with SPA tools. In the engineering education context we would characterize technology stewardship as a process in the service of teaching and learning that involves the design, adoption or adaptation of educational technology and the subsequent facilitation of its use.

Various authors have referred to the dangers of making technology selection decisions which are not grounded on sound pedagogical foundations [33-34], and a strength of Wenger's approach is that he places learning and its facilitation at the centre of the process from which subsequent decisions about technology will flow.

Participants in the SPEE-IGIP Flash Moment were

- Engaged in reflection on personally memorable learning experiences in both formal and non-formal settings;

- Acquired hands-on user experience of the online self and peer assessment tool SparkPlus;

- Discussed the concept of technology stewardship in the context of decision-making with regard to SPA online tools;

- Discussed practical aspects of the facilitation of SPA tools in education - although examples presented are taken from the context of engineering education, the underlying principles and practice have broad applications wherever collaborative project work is used.

Individual participants had the opportunity of accessing an online application hosted on an overseas server. 


\section{END NOTES}

This paper stresses two main aspects:

- First the importance of Education Societies towards the enhancement of new teaching methodologies continuously adapted to the new publics that reach higher education year after year. Additionally, it is also pointed how important it is the collaboration between existing societies, namely in the field of Engineering Education, in order to share ideas, tools, and to contribute in a more efficient way to the progress, in general, of Education strategies.

- Secondly the paper highlights the contribution of ITs to Engineering Education, discussing, based on case studies, different approaches which can be followed to enhance the learning outcomes of the students, stressing the complementarity between those approaches and the wide range of solutions already available. ITs allow, in fact, the development of educational tools of easy access, which introduce a new degree of flexibility in Engineering Education. It is most important, nevertheless to promote global initiatives both for their sharing and construction.

\section{ACKNOWLEDGMENT}

The authors wish to acknowledge all the colleagues and collaborators namely Adélio Mendes, Jaime Villate and Susana Leitão, Paulo Gil, Amâncio Santos, Gonçalo Nunes and Miguel Vieira and to their supporting institutions.

\section{REFERENCES}

[1] M. E. Auer, A. Pester and D.G Zutin, Open Source Portal for Online Laboratories, 2007.

[2] http://icampus.mit.edu/ilabs/architecture, last visited 25.05.2009

[3] Resource Description Framework. URL: http://www.w3.org/RDF/ - Last visited in 03/2009.

[4] D. Allemang ,J. Hendler, Semantic Web for the Working Ontologist: Effective Modeling in RDFS and OWL, Elsevier, 2008.

[5] Dublin Core. URL: http://dublincore.org/

[6] Draft Standard for Learning Object Metadata, IEEE-publication 2002 - URL: $\underline{\text { http://ltsc.ieee.org/wg12/ }}$

[7] SKOS - Simple knowledge Organization System. URL: http://www.w3.org/2004/02/skos/

[8] Allemang, D., \& Hendler, J. (2008), Semantic Web for the Working Ontologist: Effective Modeling in RDFS and OWL, Burlington, MA:Morgen Kaufmann Publ.

[9] Auer, M. E., Garbi Zutin, D., Maier, C., \& Niederstätter, M., (2010). Online Laboratory Metadata - Reference Model Specification. Retrieved July 13, 2010, from http://ccol.cti.ac.at/onlineLab/

[10] N. S. Edward, "The role of laboratory work in engineering education: student and staff perceptions," International Journal of Electrical Engineering Education, vol. 39, no. 1, pp. 11-19, 2002.

[11] D. Oblinger and J. Oblinger, Educating the Net Generation Introduction, Transforming education trough information technologies, Educose, 2005.

[12] Restivo, M.T. Lopes, A.M. dos Santos Machado, L. de Moraes, 1124-1129, Adding tactile information to remote \& virtual Labs, Global Engineering Education Conference, 2011 IEEE, Amman, Jordan, April 4-6, http://dx.doi.org/10.1109/EDUCON.2011.577 3287

[13] D. D. Teixeira, F. J. L. Pereira, J. F. B. Carvalho, S. M. B. Leitão, R. A. G. Bencatel, J. E. Villate, Maria T. Restivo, M. F. Chouzal and F. G. Almeida, A Michelson Interferometer For A Virtual Laboratory, CD-Rom Proceedings M2D'2006, 5th International Conference on Mechanics and Materials in Design, Session 10-E, 24/26 Julho 2006, FEUP, Portugal.
[14] M.T. Restivo, J. Villate, F. Almeida, F. Chouzal, R. Magalhães and I. Menezes, The Michelson Interferometer: a learning object, Proceedings of REV2007, Porto, Portugal, 2007.

[15] R. Jia, S. Xu, S. Gao, EL-S. Aziz, S. Esche, and C. Chassapis, "A Virtual Laboratory on Fluid Mechanics," American Society for Engineering Education, Chicago, IL, 2006.

[16] D. Schofield, E. Lester, and J. A. Wilson, "Virtual Reality Interactive Learning Envirenments," EE2004, Wolverhampton, UK, 225231.

[17] J. C. Marques, M. T. R., A. A. Sousa, F. Castro, J. Portela, C. M. Silva, and R. Delgado, "Structural mechanics: a didactic experimental set-up and its virtual tool," International Conference on Emerging e-learning Technologies and Applications, The High Tatras, Slovakia, 11-13 September, 2008.

[18] R. Batista, C.V. Carvalho, Learning Through Role Play Games, Proceedings of FIE 2008 - 38th IEEE Annual Frontiers in Education Conference, October 2008

[19] Dewey, J. Experience and Education, Kappa Delta (now Collier), New York, 1938

[20] M.G. Rasteiro, L.M. Ferreira, J.C. Teixeira, F.P. Bernardo, M.G. Carvalho, A.G. Ferreira, R.Q. Ferreira, F.P. Garcia, C.G. Baptista, N.M. Oliveira, M.M. Quina, L.O. Santos, P.A. Saraiva, A.M. Mendes, F.M. Magalhães, A.S. Almeida, J.F. Granjo, M. Ascenso, R.M. Bastos, and R. Borges, "LABVIRTUAL - a Virtual Platform to Teach Chemical Processes", Education for Chemical Engineers, Vol. 4, No. 1, 2009, pp. e9-19. http://dx.doi.org/10.1016/j.ece. 2009.02.001

[21] Bell, J. T. and Fogler, H. S., The Application of Virtual Reality to Chemical Engineering and Education, in Proc. AIChE annual meeting, Miami, USA, Nov. 1998, session 170.

[22] R.M. Felder, "Teaching engineering in the 21 st century with a 12th-century teaching model: how bright is that?", Chemical Engineering Education, Vol. 40, No. 2, 2006, pp. 110-113.

[23] Wilson, S., O. Liber, M. Johnson, P. Beauvoir, P. Sharples and C. Milligan. Personal Learning Environments: Challenging the dominant design of educational systems. Journal of e-Learning and Knowledge Society, vol.3 (2), 2007.

[24] Cardoso, A., M. Vieira and P. Gil, A Remote and Virtual Lab with Experiments for Secondary Education, Engineering and Lifelong Learning Courses, $1^{\text {st }}$ Conference exp.at'11, Lisbon, Portugal, 2011.

[25] D. Johnson, R. Johnson and K. Smith (1991), "Cooperative Learning: Increasing College Faculty Instructional Productivity", ASHE-ERIC Report on Higher Education, Washington, D.C.: The George Washington University, retrieved 30/2/2007 from http://fc1.tamu.edu/index.html

[26] D. R. Paulson, "Active Learning and Cooperative Learning in the Organic Chemistry Lecture Class", J. Chem. Educ., vol. 76, no. $1136,1999$.

[27] P. Willmot and A. R. Crawford, "Peer Review of team marks using a web-based tool: an evaluation", Engineering Education, Journal of the Higher Education Academy Engineering Subject Centre, vol 2, no. 1, pp. 59-66, 2007.

[28] K. Willey and A. Gardner, "Changing students' perceptions of self- and peer assessment", in Proc. Research in Engineering Education Symposium, Cairns, Australia, 2009.

[29] B. Beamish, M. Kizil, K. Willey and A. P. Gardner, "Monitoring mining engineering undergraduate perceptions of contribution to group project work", in Proc. 20th Australasian Association for Engineering Education (AAEE) Conference, Adelaide, Australia, pp. 318-325, 2009.

[30] P. Neto, B. Williams and I. Carvalho, "Towards technology stewardship: tools for encouraging student engagement", in Proc. Research in Engineering Education Symposium, Madrid, 2011, retrieved 12/10/ 2011 from http://www.contigovoy.es/rees/ submissions/rees2011 submission 78.pdf

[31] E.U.A. (2011) "Quality Assurance and Accountability, European University Association", retrieved 12/10/ 2011 from http://www.eua.be/eua-work-and-policy-area/quality-assurance/

[32] E. Wenger, N. White and J. Smith, Digital Habitats, stewarding technology for communities, CPsquare, 2009. 
[33] A. W. Bates and G. Poole, Effective teaching with technology in higher education. Foundations for success. San Francisco: JosseyBass, 2003

[34] D. Laurillard, "The pedagogical challenges to collaborative technologies". International Journal of Computer-Supported Collaborative Learning, vol 4, no. 1, pp 5-20, 2009. http://dx.doi.org/ $10.1007 / \mathrm{s} 11412-008-9056-2$

\section{AUTHORS}

Alberto Cardoso is Assistant Professor at the Informatics Engineering of the University of Coimbra and is a senior researcher at the Centre for Informatics and Systems of the University of Coimbra and co-leader of SPEE working Group of IT's in Engineering Education. (email: alberto@dei.uc.pt).

Carlos Vaz de Carvalho is a Professor at the Instituto Superior de Engenharia do Porto and responsible for the R\&D Group GILT-Graphics, Interaction and Learning Technologies. (e-mail: cmc@isep.ipp.pt).

Fernão de Magalhaes is with the Faculty of Engineering of University of Porto and member of SPEE working Group of IT's in Engineering Education (e-mail: fdm@fe.up.pt)

Pedro Neto is a senior lecturer at the ESTBarreiro School of Setubal Polytechnic Institute and an associate member of the Instituto de Engenharia de Estruturas, Território e Construção of Instituto Superior Técnico, Technical University of Lisbon and member of SPEE working Group of IT's in Engineering Education (e-mail: pedro.neto@estbarreiro.ips.pt)

M. Graça Rasteiro is Associate Professor of Chemical Engineering at the University of Coimbra, Portugal, President of the Chemical Processes Research Center from the same university, a member of the board of directors of the Ordem dos Engenheiros-Centro and leader of SPEE working Group of IT's in Engineering Education (email: mgr@eq.uc.pt).

M. Teresa Restivo is with the Faculty of Engineering of University of Porto and with Institute of Mechanical Engineering, IDMEC-Pole FEUP, Porto, Portugal, where coordinates the UISPA research unit. Presently is President of Portuguese Society of Engineering Education SPEE and IGIP Executive Committee Member (e-mail: trestivo@igip.org).

Danilo G. Zutin is the IGIP Secretary General and research assistant at the Systems Engineering Department at the Carinthia University of Applied Sciences, Villach, Austria.

Bill Williams is a senior lecturer at the ESTBarreiro School of Setubal Polytechnic Institute and an associate member of the Centre for Management Studies of Instituto Superior Técnico, Technical University of Lisbon member of SPEE working Group of IT's in Engineering Education(e-mail: bill.williams@estbarreiro.ips.pt)

Submitted 11 December 2011. Published as resubmitted by the authors on 13 January 2012. 